\title{
Pharmacokinetics of IV and oral acetyl-L-carnitine in a multiple dose regimen in patients with senile dementia of Alzheimer type
}

\section{Parnetti ${ }^{1}$, A. Gaiti ${ }^{2}$, P.Mecocci ${ }^{1}$, D.Cadini ${ }^{1}$, and U.Senin ${ }^{1}$}

${ }^{1}$ Institute of Gerontology and Geriatrics, Perugia University Medicine School, Perugia, Italy

${ }^{2}$ Institute of Biochemistry and Clinical Chemistry, Perugia University Medicine School, Perugia, Italy

Received: December 3, 1990/ Accepted in revised form: May 31, 1991

Eur J Clin Pharmacol (1992) 42: 89-93

The following errors occurred in the above paper:

Summary: 10th line, delete "given twice";

12 th line, substitute " $1.5 \mathrm{~g} /$ day" for " $2.0 \mathrm{~g} /$ day."

Table 1:

In section C, after "infused over 5 min" add the following: "at 0800 and 1600 hours";

In section $\mathrm{D}$, substitute

"ALC.HCl $1500 \mathrm{mg} /$ day" for

"ALC.HCl $2000 \mathrm{mg} /$ day."

Subjects and methods

lines 21-22: change to "of $1.5 \mathrm{~g}$ was given as

follows: $500 \mathrm{mg}$ at $08.00,12.00$ and at 16.00 hours."

The authors apologise for the inconvenience. 